\title{
Investigation on the effect of moisture on AC breakdown voltage of refined, bleached, and deodorized palm oil
}

\begin{abstract}
The effect of moisture on the AC breakdown voltage of palm oil was studied in this paper. The type of palm oil used in this study was Refined, Bleached and Deodorized Palm Oil (RBDPO) olein. RBDPO with different moisture contents were prepared by oven drying method. The AC breakdown voltage measurement was carried out based on ASTM D1816 at a gap distance of $1 \mathrm{~mm}$. The AC breakdown voltage data were analyzed statistically by normal, lognormal and Weibull Cumulative Distribution Function (CDF). It is found that the AC breakdown voltage of RDBPO decreases almost exponentially as the moisture content increases. Weibull CDF can represent most of the AC breakdown voltage data of RBDPO at different moisture content.
\end{abstract}

Keyword: Refined; Bleached and deodorized palm oil; AC breakdown voltage; Moisture; Cumulative distribution function 